\title{
Footprints of Human Resource in Banking Sector
}

\author{
Rajani H. Pillai'1, R. Vedapradha², Candida Smitha1, A. Suriya Kumari1 \\ ${ }^{1}$ Department of Commerce, Mount Carmel College (Autonomous), Bangalore, India \\ ${ }^{2}$ Department of Commerce, St. Joseph's College of Commerce (Autonomous), Bangalore, India \\ Email: vedahariharan@gmail.com
}

How to cite this paper: Pillai, R.H., Vedapradha, R., Smitha, C. and Kumari, A.S. (2019) Footprints of Human Resource in Banking Sector. Journal of Human Resource and Sustainability Studies, 7, 388-396. https://doi.org/10.4236/jhrss.2019.73025

Received: July 4, 2019

Accepted: July 30, 2019

Published: August 2, 2019

Copyright (c) 2019 by author(s) and Scientific Research Publishing Inc. This work is licensed under the Creative Commons Attribution International License (CC BY 4.0).

http://creativecommons.org/licenses/by/4.0/

(c) (i) Open Access

\begin{abstract}
Purpose: Human resource plays a pivotal role in the overall development of any organization irrespective of technological changes taking the lead. The study aims to analyze the role of human resource in the Merchant banks that facilitate in offering quality services rendered based on the decision making comprising of confidentiality, analytical skills, and problem-solving ability. Design/Methodology/Approach: 50 respondents from the Merchant banks operating in urban Bangalore were surveyed to collect the primary data collected based on a structured questionnaire using a stratified sampling method. Confidentiality, analytical skills, problem-solving ability, technology \& service are the variables used to test the Structural Equation Model (SEM) using SPSS AMOS (Analysis of Movement variance). Findings: SEM has been applied to validate the model fit to test if there is a significant effect of human resource in the decision making for the Merchant banking services rendered. The findings resulted that confidentiality is the most influencing path in the model with standardized coefficients being 0.986 and followed by problem-solving ability being 0.972 . Originality/Value: Artificial Intelligence has been taking over every aspect of the business reducing the workforce in the modern era of globalization as technology-enabled systems can be more accurate and useful in decision making, and human resource plays a pivotal role in interpreting the systems.
\end{abstract}

\section{Keywords}

Merchant Banking, Fraud Analysts, Structural Equation Model (SEM), Artificial Intelligence

\section{Introduction}

Banking is one of the most promising service industries that facilitate the flow of 
money in the economy and plays a significant role in the development of a nation. They are highly regulated financial institutions, which brings stability to the economy as they have access and stores information related to their clients, which are very sensitive. Customer relationship management has been a significant area of focus in the industry to improve the service quality, retention of existing clients, and attract new clients. Stringent regulations and increasing competition have made banks to create an edge over others by implementing innovative technology in their business models [1].

Human resource in the banks handles the complicated financial resources and manages the economic risks at a broader level that poses many challenges. This emphasizes on efficient and skilled human resources who can integrate cognitive thinking skills with technology. Interaction with customers and clients can create more business and generate revenues [2]. Incidents of identity theft, bank fraud, corporate accounting scandals, and online embezzlement have to be addressed more scientifically, which can be prevented by human intervention. It creates more employment opportunities for fraud analysts in the Merchant banks as well.

Merchant banking is the most challenging and unique segment of banking that requires critical personnel to be more proactive in the area of portfolio management, reconciliation, risk management, and client reporting at various levels of operations namely front end, middle end, and back end. Employees in these banks are playing a very crucial role because they refrain from disclosing any form of financial market-related information. They must adhere to the compliance, be capable of making timely decisions in the area of the asset class, and risk undertaking ability after analysis of return [3]. They also must ensure the fund is left unattended when there is excess cash contribution by the client, fund likely to be overdrawn. Timely communication, validating of credibility, multiple source verification, and effective decision making require experience. Confidentiality is the expectation as the funds tend to seed with a huge quantum of money which can be invested only by financial institutions, central banks, and high net individuals. The entire business can be turned upside down if there is any ignorance at any level by these employees who offer the banking solutions [4].

The manuscript is organized as follows with the introduction of the concept, and the research gap in exploring the importance of human resource in this digital world. Theoretical background and conceptual framework enabled in laying the foundation to the research objectives in assessing the quality service rendered by the employees. The structural equation model has been an attempt to develop a model to statistically fit the objective and facilitate in testing the hypothesis created which confirmed the importance and significant contribution of human resource in the Merchant banks during the delivery of quality service.

\section{Theoretical Background}

A theoretical framework can be adapted to measure the efficiency of the banking services considering the human resource as an essential component that in turn, 
has an impact on the quality services rendered and the overall performance of the bank [5]. Information technology is revamping the functionalities of the business to a significant level concerning to workforce and their sustainability; human resource management plays a vital role in bringing considerable changed in the business operations [6]. Customer relationship management facilitates banks to acquire new clients, retain existing customers, and attract prospective future customers who require active integration between technology and eminent personnel ultimately maximizing the value of a business [7]. PCA (Prompt Corrective Actions) and DEA (Data Envelopment Analysis) models are adopted to evaluate the efficiency of decision making in banks that support the overall performance of the banks. These models focus on a framework to ensure the sound financial health and the analysis, which requires the solutions to the various problems addressed respectively [8]. Robust and effective human resource strategies can contribute towards better management of back-end employees in the Merchant banks encourages banks with international business operations to handle the responsibilities and activities performed comprise of an important asset in the organization [9]. The Commitment of the employees towards the organization with embed training programs, job experience, mentoring, which leads to the satisfaction of the employees, which results, in turn, offering quality services to the clients. Trust and loyal workforce ensure in bringing more productivity in the business [10]. Human resource plays a vital role while framing economic policies, and financial regulations to facilitate maintaining policies of banking secrecy, stability in a financial position [11]. Technological innovations have always shaped the banking business in a dynamic angel resulting to more redefined integrated strategies impacting the customer relationship, innovative business models, designing the customized products and services, and addressing financial criticalities which ponder over the relationship between technology and financial leverages [12].

\section{Conceptual Framework}

The Banking sector has always been facing challenges towards people and risk management in their operations. Effective risk management can result to be impossible without the quality and skilled workforce. Human resource plays a pivotal role in the Merchant banks rendering services in the critical areas like Core HR activities, payroll management, training \& development, professional services, recruitment, talent management, and workforce management. The current business firms have realized the significance of their human resource by treating them as human capital on the assets side of the balance sheet rather than concluding as a cost to the company.

\section{Empirical Research}

\subsection{Research Model}

Scope of the survey 
The geographical coverage of this survey belongs to urban Bangalore in Karnataka, India.

\section{Statement of the problem}

Artificial Intelligence has been taking over every aspect of the business in the modern era of globalization. Though technology-enabled systems can be more accurate and useful in decision making, human resource plays a pivotal role in interpreting the systems. Hence, the researcher has attempted to analyze the role of human resource in Merchant banks concerning decision making, problem-solving ability.

Objectives

To assess the impact of human resource on the services offered by Merchant banks.

\section{Sample size}

The respondents belong to employees of Merchant banks operating in Bangalore urban were chosen for the study.

\section{Sampling technique}

Stratified random sampling method comprises of arriving at a specific sample size involving the division of the population into smaller groups formed as "Strata" means certain common characteristics of the population chosen for the study. The stratified sampling technique has been applied to collect the sample size of 50 respondents.

\section{Methods of data collection}

A structured questionnaire based on the Linkert scale was designed to collect the primary data from the respondents working in the leading Merchant banks operating in urban Bangalore.

\section{Variables}

Confidentiality, analytical skills, problem-solving ability, technology, service.

data analysis and tool

Structured Equation Model and Statistical tool applied is the Statistical Package for Social Science (SPSS) with Analysis of Moment Structures (AMOS).

Limitations of the study

The foreign Merchant banks operating only in Bangalore Urban. The concept from the area chosen for the study is very new, and there are not many empirical contributions in this field of Merchant banking due to which having a deeper understanding is still to be explored and has limited the researcher.

\subsection{Scope for Further Research}

There is scope for further research in the area of application of blockchain \& artificial intelligence in various segments of $\mathrm{HR}$, can perform comparative study before \& after implementing the technology. Further study may be looked into in this area by applying advanced methodologies.

\subsection{Hypothesis}

$\mathrm{H}_{0}$ : There is no significant impact on human resource in decision making for 
Merchant banking services rendered.

$\mathrm{H}_{1}$ : There is a significant impact on human resource in decision making for Merchant banking services rendered.

\section{Results}

Reliability test of internal consistency was performed to measure the reliability, which resulted (Cronbach $\alpha=0.902$ ) for the 50 items considered for the study based on the formula as below.

$$
\frac{\frac{Z^{2} \cdot p(1-p)}{e^{2}}}{1+\left(\frac{Z^{2} \cdot p(1-p)}{e^{2} N}\right)}
$$

where $N=60, e=5$ per cent, $z=1.96$, thus arriving at a sample size of 50 .

Figure 1 reflects the SEM model based on the standardised coefficients on service in Merchant banks applied for the testing of goodness of fit in the quality services offered by the competitive human resource, who play an eminent role in decision making with components of HR1 (Confidentiality), HR2 (Analytical skills), HR3 (Problem solving ability), and HR4 (Technology) in an investment bank. e1, e2, e3, and e4 being those influencing factors of the variables, namely ethical values, professionally certified, experience, and compliance, respectively.

Table 1 reflects the model fit summary, found that the calculated $p$-value is 0.713, which is higher than 0.05 , indicating the model fits perfectly. It resulted that GFI, AGFI, NFI, and CFI are more significant than 0.90 indicates that it is perfect fit. RMR and RMSEA are less than 0.08 .

Table 2 shows that the unstandardized coefficient of Service offered based on confidentiality is 1.00 , analytical skills are 0.537 , the problem-solving ability is 0.93 , and Technology is 0.78 . The estimated positive sign implies that such effect is positive that confidentiality, analytical skills, problem-solving ability, and technology would increase by 1.00 for every client and this coefficient value is significant at 1 per cent level.

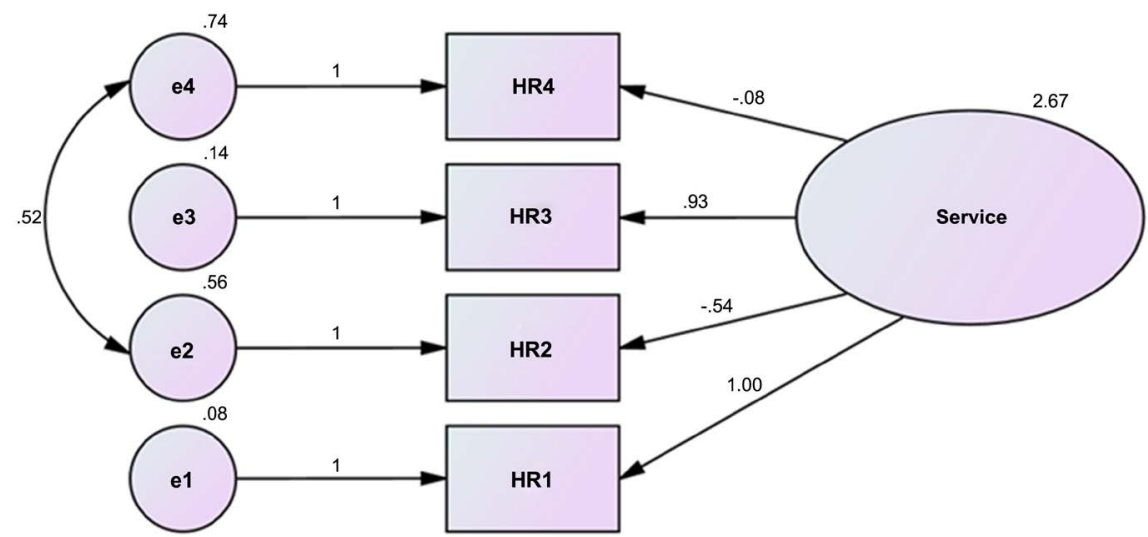

Figure 1. Structural equation model (SEM) based on standardised coefficient on service in Merchant banks. Source: Computed based on primary data. 
Table 1. Model fit summary of structural equation model.

\begin{tabular}{ccc}
\hline INDICES & VALUE & SUGGESTED VALUE \\
\hline Chi-square value & 1.75 & - \\
DF & 1.00 & - \\
$p$-value & 0.713 & $>0.05$ (Hair et al., 1998) \\
Chi-square value/DF & 0.135 & $<5.00$ (Hair et al., 1998) \\
GFI & 0.999 & $>0.90$ (Hu and Bentler, 1999) \\
AGFI & 0.986 & $>0.90$ (Hair et al. 2006) \\
NFI & 0.999 & $>0.90$ (Hu and Bentler, 1999) \\
CFI & 1.000 & $>0.90$ (Daire et al., 2008) \\
RMR & 0.006 & $<0.08$ ( Hair et al. 2006) \\
RMSEA & 0.000 & $<0.08$ ( Hair et al. 2006) \\
\hline
\end{tabular}

Source: Computed from primary data.

Table 2. Variables in the structural equation model analysis.

\begin{tabular}{cccccccc}
\hline \multicolumn{2}{r}{ Variables } & & $(B)$ & S.E of B & $($ Beta $)$ & t value & $p$-value \\
\hline Confidentiality & $\leftarrow$ & Service & 1.000 & - & 0.986 & - & - \\
Analytical skills & $\leftarrow$ & Service & 0.537 & 0.68 & 0.760 & 7.891 & $<0.001^{* *}$ \\
Problem solving & $\leftarrow$ & Service & 0.930 & 0.45 & 0.972 & 20.64 & $<0.001^{* *}$ \\
Technology & $\leftarrow$ & Service & 0.78 & 0.76 & 0.146 & 1.019 & 0.308 \\
\hline
\end{tabular}

**Significant at 0.001 per cent level. Source: Computed from primary data; (B): Unstandardized co-efficient, (Beta): Standardised co-efficient.

\section{Findings \& Discussion}

Analytical skills combined with technology-enabled systems, lead to better decision making by the various key personnel in the company who hold designations like portfolio managers, portfolio analysts, and compliance officers. Based on Standardised coefficient, confidentiality $(0.986)$ is the most influencing path in this SEM model, followed by Problem-solving ability (0.972), analytical skills (0.760) and technology is the least influencing factor (0.146). Employees at the middle office and back-end offices are expected to possess the ability to solve complex problems encountered during the operations so that the decision making at the front office becomes easier and robust. Hence, SEM has proved that confidentiality (0.986) is the most influencing path followed by problem-solving ability (0.972) based on Standardised coefficient. Since the parameters of the model fit summary table has the values within the threshold concerning GFI, AGFI, NFI, CFI, RMR \& RMSEA along with the probability value falling within the permissible range, the null hypothesis gets rejected at 0.001 percent level of significance. Hence, the alternative hypothesis is accepted which proves that the designed model fits perfectly to the concept and indeed human resource play an important role during this digital era and cannot be replaced by any artificial in- 
telligence of innovative technologies. There are many other factors which can influence the quality of service rendered apart from the variables, namely confidentiality, analytical skills, problem-solving skills, and technology. However, the researcher has focused on the chosen variables as these can be considered as the key factors in rendering the quality service, which requires rational thinking by human resources.

\section{Conclusion}

Human Resource Management provides competitive operational expertise leading towards profitability and improves the efficiency of the business. The most important attribute in these banks is the confidentiality about the strategies adopted, key information which could influence the strategic move of the business, timely reporting to the clients and other parties like custodian and brokers, non-disclosure of the client details with either other employees of the same organization of competitors. Trust and better customer relationship management are the key components of success to an investment bank. The results obtained from the statistical tool reflect that for any organization to create an edge over others and to sustain in the long run, confidentiality towards the clients, stakeholders are the most important component to retain the goodwill. However, the decision-making skills always vest in the hands of the human resource irrespective of advancement in technology when the results are derived from the systems. Problem-solving skill is another important factor for the analysts to empower the Merchant banks who are proactive in fixing the issues at the earliest ensuring there is no impact on the fund management, goodwill and business due to the delay in addressing the complex problems encountered by the employees. The variables in the model analysis also confirm that technology does not affect the intellectual skills of the human resource as it can only aid in smoothening the process flow, reducing the cost, reducing the workload of employees, and creating fool-proof documents and mechanism but cannot replace the human brains who have ultimately created this technology. Hence, the delivery of effective service to the clients maximum depends on the components of confidentiality, problem-solving skills, and analytical skills but not dependent on the technology.

\section{Conflicts of Interest}

The authors declare no conflicts of interest regarding the publication of this paper.

\section{References}

[1] Kokemuller, N. (2017) The Importance of CRM in the Banking Sector. https://bizfluent.com/facts-6883122-importance-crm-banking-sector.html

[2] Josh, J. (2016) Why Human Resource Management Is Important for Banks? https://www.jagranjosh.com/articles/why-human-resource-management-is-importa nt-for-banks-1464354319-1 
[3] Grasshoff, G., Lerbinger, P., Sinn, W. and Wintels, S. (2005) Value Management in Merchant Banking. In: Lange, T.A. and Schulze, H., Eds., Wertmanagement in Banken, Gabler Verlag, Wiesbaden. https://doi.org/10.1007/978-3-322-90794-3_6

[4] Ingram, D. (2017) Role of HR in Banking. https://bizfluent.com/info-7986688-role-hr-banking.html

[5] Mukherjee, A., Nath, P. and Pal, M. (2003) Resource, Service Quality and Performance Triad: A Framework for Measuring Efficiency of Banking Services. Journal of the Operational Research Society, 54, 723-735.

https://doi.org/10.1057/palgrave.jors.2601573

[6] Blount, Y., Castleman, T. and Swatman, P.M.C. (2003) E-Commerce and Human Resource Management: Theoretical Approaches and Issues for the Banking Industry. In: Andersen, K.V., Elliot, S., Swatman, P., Trauth, E. and Bjørn-Andersen, N., Eds., Seeking Success in E-Business. A Multidisciplinary Approach, Springer, Boston, MA.

[7] Onut, S., Erdem, I. and Hosver, B. (2008) Customer Relationship Management in Banking Sector and a Model Design for Banking Performance Enhancement. In: Minai, A.A. and Bar-Yam, Y., Eds., Unifying Themes in Complex Systems IV, Springer, Berlin, Heidelberg, 370-378.

https://doi.org/10.1007/978-3-540-73849-7_41

[8] Dash Wu, D. and Wu, D. (2010) Performance Evaluation and Risk Analysis of Online Banking Service. Kybernetes, 39, 723-734. https://doi.org/10.1108/03684921011043215

[9] Newenham-Kahindi, A. (2013) Human Resource Strategies for Managing Back-Office Employees in Subsidiary Operations: The Case of Two Investment Multinational Banks in Tanzania. In: Newenham-Kahindi, A., Kamoche, K.N., Chizema, A. and Mellahi, K., Eds., Effective People Management in Africa, Palgrave Macmillan, London. https://doi.org/10.1057/9781137337177

[10] Syed, N.A., Cheema, F.A., Kamran, A. and Khalid, H. (2014) Impact of Human Resources Practices upon Turnover and Productivity in the Banking Sector of Pakistan. In: Xu, J., Fry, J.A., Lev, B. and Hajiyev, A., Eds., Proceedings of the Seventh International Conference on Management Science and Engineering Management, Springer, Berlin, Heidelberg, 1139-1152.

https://doi.org/10.1007/978-3-642-40081-0_96

[11] Masciandaro, D. and Balakina, O. (2015) Banking Secrecy, Regulation and Supervision. In: Banking Secrecy and Global Finance: Economic and Political Issues, Palgrave Macmillan, London. https://doi.org/10.1057/9781137400109

[12] Campanella, F., Della Peruta, M.R. and Del Giudice, M. (2017) The Effects of Technological Innovation on the Banking Sector. Journal of the Knowledge Economy, 8, 356-368. https://doi.org/10.1007/s13132-015-0326-8 


\section{Appendix}

- GFI-Goodness of Fit Index

- AGFI-Adjusted Goodness of Fit Index

- NFI-Normed Fit Index

- CFI-Comparative Fit Index

- RMR-Root Mean Square Residuals

- RMSEA-Root Mean Square Error of Approx 